\title{
A Game Theoretic Model for Trading Pollution Discharge Permits in River Systems
}

\author{
Mohammad Reza Nikoo, Reza Kerachian, Mohammad Hossein Niksokhan \\ and Pouyan Hatami Bahman Beiglou
}

\begin{abstract}
In this paper, by combining a two-person nonzero-sum game, a multi-objective genetic algorithm and a cooperative game, we present a new game theoretic methodology for trading pollution discharge permits in rivers. A trade-off curve between the average treatment level of dischargers and fuzzy risk of low water quality is gained using the optimization model. Then, by using the two-person nonzero-sum game, the best non-dominated solution is chosen from the trade-off curve. The treatment costs of dischargers corresponding to the selected solution are reallocated among dischargers participating in a coalition and side payments are calculated. The proposed model is applied to the Zarjub River in Iran to illustrate its efficiency and applicability.
\end{abstract}

Index Terms-Trading Pollutant Discharge Permits, Fuzzy Bi-matrix Game, Water Quality.

\section{INTRODUCTION}

In Tradable Discharge Permit (TDP) programs, pollution can be considered as a transferable property right with tangible value. In these programs, dischargers who can cost-effectively remove its pollutants more than required could sell unused permits to relatively inefficient dischargers, who will be buyers of pollutant discharge permits, discharging more wastewater than his initial discharge permit [1].

In the past decades, many studies have been carried out for developing deterministic and stochastic TDP programs. Montgomery [2] and Eheart et al. [3] proposed deterministic models for trading pollutant discharge permits in rivers. These models were not able to quantitatively characterize the risk of violating the river water quality standards.

Nishizawa [4] examined the present and potential role of effluent trading in water quality management. Eheart and $\mathrm{Ng}$ [1] discussed the weaknesses and strengths of trading pollutant discharge permits in the context of a Total Maximum Daily Load (TMDL) program. They also presented some hypothetical quantitative findings to show

Manuscript received March 15, 2011.

M. R. Nikoo is a Ph.D. Candidate at the School of Civil Engineering, University of Tehran, Tehran, Iran (e-mail: nikoo@ut.ac.ir).

R. Kerachian is an Associate Professor at the School of Civil Engineering, University of Tehran, Tehran, Iran. He is also a member of Center of Excellence for Engineering and Management of Civil Infrastructures, College of Engineering, University of Tehran (phone: +98-21-61112176; fax +98-21-66403808; e-mail: kerachian@ut.ac.ir).

M.H. Niksokhan is a Research Staff at the Water Research Institute, Tehran, Iran (e-mail: niksokhan@ut.ac.ir).

P.H.B. Beiglou is a M.Sc. Student at the School of Civil Engineering, University of Tehran, Tehran, Iran (e-mail: hatami.pouyan@ut.ac.ir). the circumstances under which a regional administrator might wish to adopt a trading permit program. Hung and Shaw [5] proposed a Trading Ratio System (TRS) methodology for TDP in river systems considering the fact that water flows to the lowest level unidirectionally.

$\mathrm{Ng}$ and Eheart [6] focused on stochastic environmental modeling and utilized Mean-value First-Order Second-Moment (MFOSM) method to illustrate how trading discharge permit will affect the reliability of environmental quality. Mesbah et al. [7] suggested an extended version of the TRS, which can be used for Biochemical Oxygen Demand (BOD) and Dissolved Oxygen (DO) management in river systems. They also used Bayesian Networks (BNs) for developing probabilistic rules for real-time trading discharge permits.

Recently, Niksokhan et al. [8] presented an efficient methodology for pollutant discharge permit trading in rivers considering the conflict of interests of stakeholders of the system. They used the Young bargaining theory for finding the best non-dominated solution, which provides the discharge permit trading policies.

Niksokhan et. al. [9] presented an efficient methodology for developing pollutant discharge permit trading in river systems considering the conflict of interests of involving decision-makers and the stakeholders. In their methodology, a trade-off curve between objectives was developed using the Nondominated Sorting Genetic Algorithm-II (NSGA-II). The objective functions were related to the total treatment cost and a fuzzy risk of violating the water quality standards. Finally, an optimization model provided the trading discharge permit policies.

Cole and Ritter [10] discussed the factors that can affect the effectiveness of water quality trading programs. They expressed that for a successful trading, the most basic elements which must be in place are a firm legal backing and a commitment to making equitable decisions about all aspects of a program's design. They also mentioned that economic viability of trading program is the heart of a successful water quality trading.

Mesbah et al. [11] proposed an extended version of TRS which considers the uncertainties in treatment cost functions and can be used for BOD/DO management in rivers. Then, by combining the extended TRS and a fuzzy nonlinear regression, a novel model was proposed to configure a permit-trading structure and provide decision maker with a wealth of cost-effective management strategies. They used their model for trading water pollutant discharge permits in the Zarjub river in northern part of Iran. The results showed that trading discharge permit in this river system is a 
cost-effective strategy. It was also shown that the uncertainty in the wastewater treatment cost functions can be easily considered using the fuzzy set theory.

In this Paper, a new methodology is proposed for cooperative trading pollutant discharge permits by utilizing two-person nonzero-sum game, Non-dominated Sorting Genetic Algorithms II and cooperative game theory. To evaluate the efficiency and applicability of the proposed methodology, it is applied to the Zarjub River in the northern part of Iran.

\section{MODEL FRAMEWORK}

Fig. 1 illustrates the main components of the proposed methodology. As shown in this figure, in the first step of the proposed methodology, the NSGA-II [12] provides a trade-off between the objectives, namely the average treatment level of dischargers and a fuzzy risk of low water quality. Then, by applying the two-person game, the best non-dominated solution on the trade-off curve is selected.

A single objective optimization model and cooperative game theory are employed for fairly reallocation of treatment cost to participants in a coalition and defining side payments. The fuzzy risk can be estimated at checkpoints as [13]:

$$
F R=\sum_{c_{\min }}^{c_{\max }} \mu_{W}(c) p(c)
$$

Where, $\mu_{\mathrm{w}}(\mathrm{c})$ is the membership function of the fuzzy event of low water quality based on the concentration of a water quality indicator $(\mathrm{c}), \mathrm{c}_{\min }$ and $\mathrm{c}_{\max }$ are minimum and maximum concentration levels of the water quality indicator, respectively and $\mathrm{p}\left(\mathrm{c}_{1}\right)$ is probability density function (PDF) of the concentration level of the water quality indicator.

In this paper, by applying the Monte Carlo analysis, PDF of the concentration of water quality indicator at checkpoints along the river are attained considering the PDF of random variables in the water quality simulation model.

To select the best non-dominated solution from the trade-off of the conflicting objectives of environmental protection agencies and dischargers, a two-person nonzero-sum game is utilized. Consider two players I and II with the mixed strategy vectors $\mathrm{x}$ and $\mathrm{y}$, respectively. Assume that $x$ is of dimensionality n-by-1 and $y$ dimensionality m-by-1. Let the n-by-m matrices $A$ and $B$ be the players $I$ and $I$, respectively. Player I maximizes over the rows of A, and II maximizes over the columns of B. Let $e$ be an n-by-1 vector of ones and I an m-by-1 vector of ones. The objective of player I is to [14]:

$$
\begin{array}{cl}
\underset{x}{\operatorname{Max}} & x^{\prime} A y \\
\text { S.t. } & e^{\prime} x-1=0 \\
& x \geq 0
\end{array}
$$

This optimization model for player II has the following form:

$$
\begin{array}{cl}
\underset{y}{\operatorname{Max}} & x^{\prime} B y \\
\text { S.t. } & l^{\prime} y-1=0 \\
& y \geq 0
\end{array}
$$

Where the primes denote the transpose. A Nash equilibrium point $\left(\mathrm{x}^{0}, \mathrm{y}^{0}\right)$ is defined as a pair of strategies $\mathrm{x}^{0}$ and $y^{0}$ where the objectives (2) and (3) are simultaneously fulfilled [15]. Therefore, we have:

$$
\begin{aligned}
& x^{0^{\prime}} A y^{0}=\max _{x}\left\{x^{\prime} A y^{0} \mid e^{\prime} x-1=0, x \geq 0\right\} \\
& x^{0^{\prime}} B y^{0}=\max _{y}\left\{x^{0^{\prime}} B y \mid l^{\prime} y-1=0, y \geq 0\right\}
\end{aligned}
$$

By a direct application of the Kuhn-Tucker necessary and sufficient conditions to the system (4), the following lemma that gives necessary and sufficient conditions for an equilibrium point is obtained [14].

Mangasarian and Stone [14] showed that a necessary and sufficient condition that $\left(x^{0}, y^{0}\right)$ be an equilibrium point of (4) is that there exist scalar values $\alpha^{0}$ and $\beta^{0}$ such that: $x^{0}, y^{0}, \alpha^{0}, \beta^{0}$ satisfy:

$$
\begin{aligned}
& x^{0^{\prime}} A y^{0}-\alpha^{0}=0 \\
& x^{0^{\prime}} B y^{0}-\beta^{0}=0 \\
& A y^{0}-\alpha^{0} e \leq 0 \\
& B^{\prime} x^{0}-\beta^{0} l \leq 0 \\
& e^{\prime} x^{0}-1=0 \\
& l^{\prime} y^{0}-1=0 \\
& x^{0} \geq 0 \\
& y^{0} \geq 0
\end{aligned}
$$

Note that $\alpha^{0}$ and $\beta^{0}$, which are the negative of the multipliers associated with the constraints (9) and (10) respectively, are also equal to the expected payoffs to $\mathrm{I}$ and $\Pi$, respectively at the equilibrium point $\left(\mathrm{x}^{0}, \mathrm{y}^{0}\right)$.

Conditions (5) and (6) were obtained by simplifying $x^{0}\left(A y^{0}-\alpha^{0} e\right)=0$ and $y^{0}\left(B^{\prime} x^{0}-\beta^{0} 1\right)=0$, respectively with the use of (9) and (10) [14].

A necessary and sufficient condition that $\left(\mathrm{x}^{0}, \mathrm{y}^{0}\right)$ be an equilibrium point of (4) is that it is a solution of the following programming problem [14]:

$$
\begin{array}{cl}
\underset{x, y, \alpha, \beta}{\operatorname{Max} \text { imize }} & x^{\prime}(A+B) y-\alpha-\beta=0 \\
\text { s.t. } & A y-\alpha e \leq 0 \\
& B^{\prime} x-\beta l \leq 0 \\
& e^{\prime} x-1=0 \\
& l^{\prime} y-1=0 \\
& x \geq 0 \\
& y \geq 0
\end{array}
$$


Where $\alpha$ and $\beta$ are scalars. The values of $\alpha$ and $\beta$ at the maximum, $\alpha^{0}$ and $\beta^{0}$, equal the expected payofls to players I and $\Pi$, respectively.

A simple example about the solving process using two-person nonzero-sum game is given here to clarify this issue:

Consider the two-person nonzero-sum game whose pay-off matrices A and B are as follows:

$$
A=\left(\begin{array}{cc}
3 & -1 \\
-1 & 2
\end{array}\right), B=\left(\begin{array}{cc}
1 & -1 \\
-1 & 4
\end{array}\right)
$$

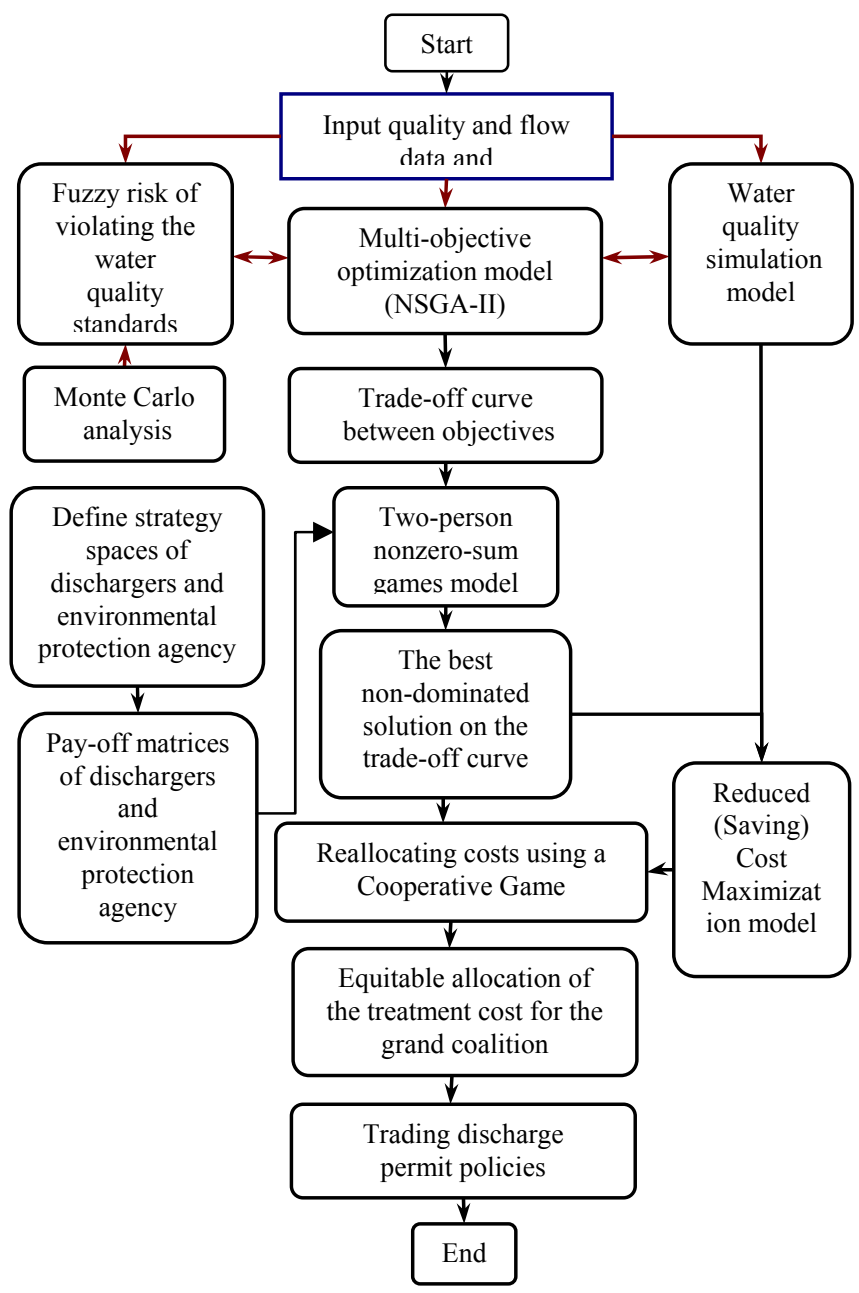

Fig. 1. Flowchart of the proposed methodology for pollution discharge permit trading in rivers

The following relations are resulted using equations 13 and 14:

$$
\begin{array}{cc}
\underset{x, y, \alpha, \beta}{\operatorname{Max} i m i z e} & {\left[x_{1} x_{2}\right]\left[\begin{array}{cc}
4 & -2 \\
-2 & 6
\end{array}\right]\left[\begin{array}{l}
y_{1} \\
y_{2}
\end{array}\right]-\alpha-\beta=0} \\
\text { s.t. } & 3 y_{1}-y_{2}-\alpha \leq 0 \\
& -y_{1}+2 y_{2}-\alpha \leq 0 \\
& x_{1}-x_{2}-\beta \leq 0 \\
& -x_{1}+4 x_{2}-\beta \leq 0 \\
& x_{1}+x_{2}=1 \\
& y_{1}+y_{2}=1 \\
& x_{1}, x_{2}, y_{1}, y_{2} \geq 0
\end{array}
$$

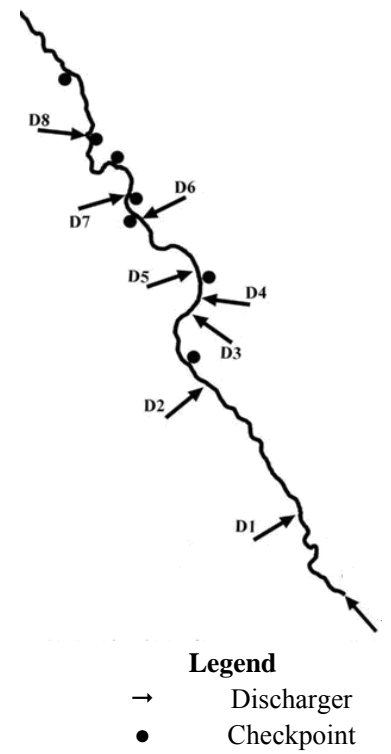

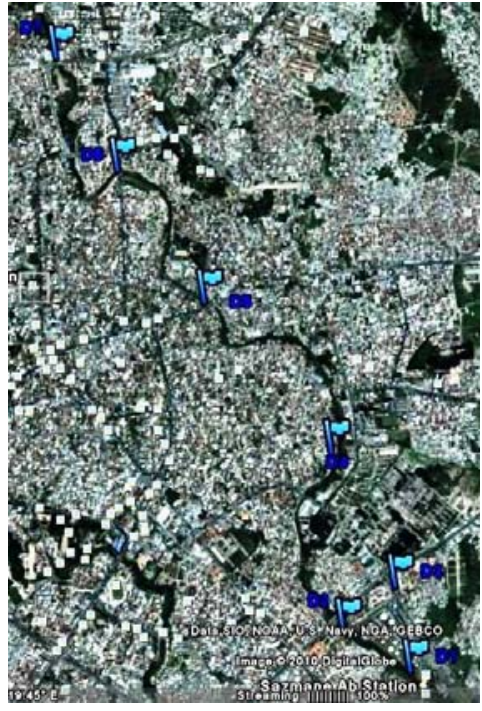

The Google Earth map of the Zarjub River
Fig. 2. A schematic map and location of pollution dischargers in the Zarjub River system

The above non-linear problem is solved using Lingo $8 \circledR$. Equilibrium points that obtained with this method is $\mathrm{x}=(0.71,0.29)$ and $\mathrm{y}=(0.43,0.57)$ with expected payoffs $\alpha=0.71$ and $\beta=0.43$ For more details about the concepts of this two-person nonzero-sum game refer to Mangasarian and Stone [14].

To reduce their treatment costs, dischargers can participate in a cooperative pollutant discharge permits trading. Cooperative cost allocation is attractive, but fairness as a key issue, still needs to be dealt with carefully. The fairness criterion cannot be satisfied by minimizing the total or average treatment cost of the system. For fairly treatment cost reallocation, Niksokhan et al. [9] utilized the cooperative game theory. In their work, the buyer and sellers of discharge permits are determined and the values of side payments among dischargers are defied by comparing the initial and reallocated treatment costs of dischargers. In this paper, the proposed cost reallocation methodology proposed by Niksokhan et al. [9] is used. Through two sub-models in that methodology, the total treatment cost is reallocated: Maximization of Total Treatment Cost Reduction (MTTCR) and Cooperative Reallocation Game (CRG).

\section{RESUlts AND DISCUSSION}

To evaluate the efficiency and applicability of the proposed trading discharge permit methodology, it is applied to the Zarjub River. The main characteristics of this river and its pollution loads can be found in Fig. 2 and [8 and 11]. In this paper, by considering a fuzzy membership function for the DO concentration (Fig. 3), the fuzzy risk of low water quality at checkpoints is calculated.

The Monte Carlo analysis is used to calculate the fuzzy risk, regarding the main random variables in the water quality simulation model, including upstream river flow, BOD concentration in headwater, headwater temperature, BOD and DO concentrations in discharging wastewaters, the BOD decay rate $(\mathrm{k})$ and the reaeration coefficient $\left(\mathrm{k}_{2}\right)$. The 
Streeter-Phelps equations [16] are used to simulate the river water quality. Five hundred Monte Carle simulations are done to calculate the PDF of DO at several checkpoints along the river. The NSGA-II gives the trade-off between the average treatment level of dischargers and the fuzzy risk (Fig. 4).

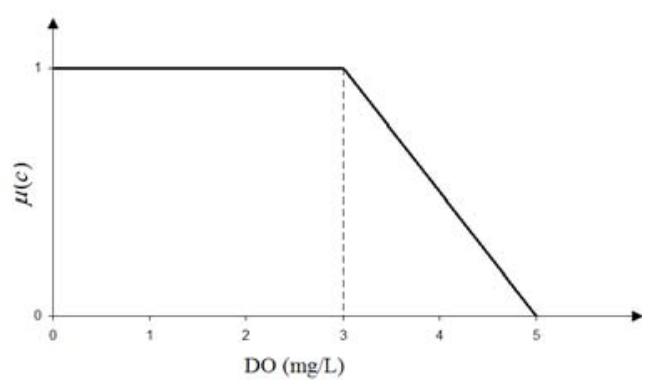

Fig. 3 The selected fuzzy membership function for low water quality

In the two-person nonzero-sum game, the pay-off matrices considered for dischargers (matrix A) and environmental protection agencies (matrix B) are as follows:

$$
\begin{aligned}
& A=\begin{array}{r}
40 \\
30 \\
70 \\
70
\end{array}\left[\begin{array}{ccccc}
0 & 0 & 0 & 0 & 0.85 \\
0 & 0 & 0 & 0.62 & 0 \\
0 & 0 & 0.5 & 0 & 0 \\
0 & 0.39 & 0 & 0 & 0 \\
0.31 & 0 & 0 & 0 & 0
\end{array}\right] \\
& B=50\left[\begin{array}{r}
42 \\
30 \\
70 \\
90
\end{array}\left[\begin{array}{ccccc}
0 & 0 & 0 & 0 & 0.15 \\
0 & 0 & 0 & 0.38 & 0 \\
0 & 0 & 0.5 & 0 & 0 \\
0 & 0.61 & 0 & 0 & 0 \\
0.69 & 0 & 0 & 0 & 0
\end{array}\right]\right.
\end{aligned}
$$

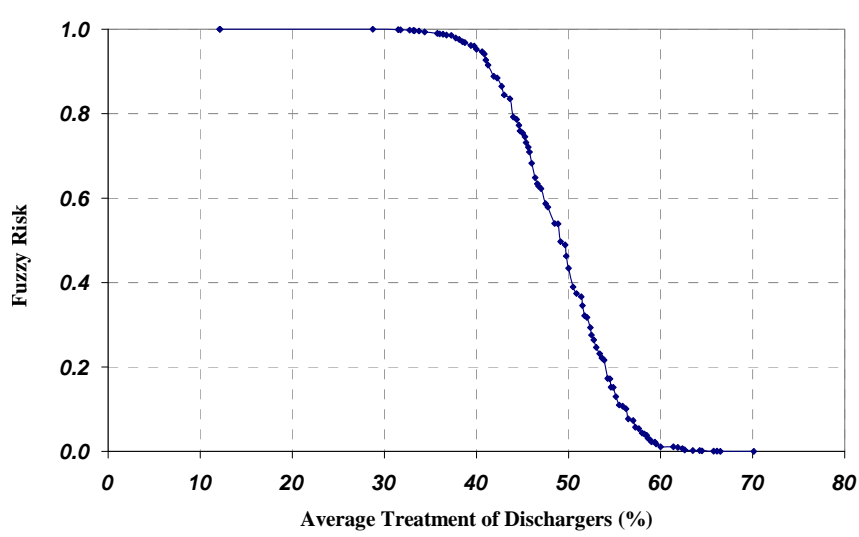

Fig. 4 Trade-off between the objectives obtained using the NSGA-II

Vectors of $(10,30,50,70,90)$ and $(42,46,50,54,58)$ are the strategy spaces of dischargers and the environmental protection agency. The optimum value for the objective function of the optimization model of the two-person game is0.54. The equilibrium point is corresponding to $\mathrm{x}=(0,0,0,0,1)$ and $\mathrm{y}=(1,0,0,0,0)$ and the expected payoffs are $\alpha=0.31$ and $\beta=0.15$.

Tables I and II present the characteristics of the selected non-dominated solution using two-person nonzero-sum game. The results show that dischargers 2, 6 and 7 can form a coalition to reduce their treatment costs. Dischargers 1 and 3 have no treatment cost and dischargers 4 and 5 should completely treat their pollution loads because they have lower treatment costs and increasing their treatment levels does not significantly improve the river water quality. For the selected coalition of dischargers, the maximum cost reduction and treatment cost of dischargers 2, 6 and 7 are calculated (Table III). TABLE I. OPTIMAL VALUES OF VARIABLES IN THE OPTIMIZATION
MODELS OF THE TWO-PERSON GAME

\begin{tabular}{|l|l|l|l|l|l|}
\hline Variable & $x_{1}$ & $x_{2}$ & $x_{3}$ & $x_{4}$ & $x_{5}$ \\
\hline Optimal value & 0 & 0 & 0 & 0 & 1 \\
\hline Variable & $y_{1}$ & $y_{2}$ & $y_{3}$ & $y_{4}$ & $y_{5}$ \\
\hline Optimal value & 1 & 0 & 0 & 0 & 0 \\
\hline
\end{tabular}

In this case, the treatment cost of discharger 6 is more than its initial treatment cost and the treatment costs of dischargers 2 and 7 are less than their initial treatment costs. Therefore, dischargers 2 and 7 have to buy discharge permits from discharge 6 . The total cost reduction, when dischargers 2, 6 and 7 form a coalition is equal to 0.253 million U.S. \$.

In this paper, a cooperative game theoretic approach, namely the Nucleolus game is utilized to equitably allocate the total cost reduction to dischargers and calculate side payments. The share of each discharger from the total cost reduction, final treatment cost after cost reallocation, and side payments are summarized in Table IV. In this table, a positive value for the side payment of discharger 6 shows that this discharger should sell discharge permit and gain money equal to its side payment. Similarly, negative values for the side payments of dischargers 2 and 7 show that these dischargers should buy discharge permits and pay money to discharger 6 equal to their side payments.

TABLE II. THE CHARACTERISTICS OF THE BEST NON-DOMINATED SOLUTION SELECTED BY USING THE TWO-PERSON NONZERO-SUM GAME

\begin{tabular}{|c|c|c|c|}
\hline Dischar & Treatment & Initial treatment cost & Fuzzy \\
\hline 1 & 0 & 0 & 31 \\
\hline 2 & 65 & 0.489 & \\
\hline 3 & 0 & 0 & \\
\hline 4 & 95 & 0.13 & \\
\hline 5 & 95 & 0.13 & \\
\hline 6 & 55 & 0.044 & \\
\hline 7 & 72 & 0.734 & \\
\hline 8 & 88 & 0.219 & \\
\hline
\end{tabular}

TABLE III. TREATMENT COST OF DISCHARGERS 2, 6 AND 7 TAKING PART IN DIFFERENT COALITIONS (MILLION U.S. \$)

\begin{tabular}{|c|c|c|c|c|}
\hline \multirow{2}{*}{$\begin{array}{c}\text { Coalition } \\
\text { among } \\
\text { dischargers }\end{array}$} & \multicolumn{3}{|c|}{$\begin{array}{c}\text { Treatment cost of } \\
\text { discharger }\end{array}$} & $\begin{array}{c}\text { Cost } \\
\text { reduction }\end{array}$ \\
\cline { 2 - 5 } & 2 & 6 & 7 & \\
\hline 2,6 and 7 & 0.325 & 0.144 & 0.545 & 0.253 \\
\hline 2 and 6 & 0.389 & 0.081 & - & 0.063 \\
\hline 2 and 7 & 0.489 & - & 0.734 & 0 \\
\hline 6 and 7 & - & 0.104 & 0.598 & 0.076 \\
\hline
\end{tabular}

TABLE IV. FINAL TREATMENT COST AND SIDE PAYMENTS OF Dischargers IN COALITION OF DischaRGERS 2, 6 AND 7 (Million U.S. \$)

\begin{tabular}{|c|c|c|c|}
\hline $\begin{array}{c}\text { Discha } \\
\text { rger }\end{array}$ & $\begin{array}{c}\text { Share of each discharger } \\
\text { from the total treatment cost } \\
\text { reduction (allocation of cost }\end{array}$ & $\begin{array}{c}\text { Reallocated } \\
\text { (final) } \\
\text { treatment cost }\end{array}$ & $\begin{array}{c}\text { Side } \\
\text { payme- } \\
\text { nt }\end{array}$ \\
\hline 2 & 0.094 & 0.394 & -0.069 \\
\hline 6 & 0.044 & 0 & 0.144 \\
\hline 7 & 0.115 & 0.619 & -0.075 \\
\hline Sum & 0.253 & 1.014 & 0 \\
\hline
\end{tabular}




\section{REFERENCES}

[1] J.W. Eheart, and T.L. Ng, "Role of effluent permit trading in total maximum daily load programs: overview and uncertainty and reliabiLy implications", Journal of Environmental Engineering, ASCE, vol. 130, No. 6, 2004, pp. 615-621.

[2] W.D. Montgomery, "Markets in licenses and efficient pollution control programs", J. Econ. Theory, vol. 5, 1972, pp. 395-418.

[3] J. W. Eheart, E.D. Brill, B.J. Lence, J.D. Kilgore and J.D. Uber, "Cost efficiency of time-varying discharge permit programs for water quality management", Water Resour. Res., vol. 23, 1987, pp.245-251.

[4] E. Nishizawa, "Effluent trading for water quality management: concept and application to the Chesapeake Bay watershed", Marine Pollution Bulletin, vol. 47, 2003, pp. 169-174.

[5] M. Hung, and D. Shaw, "A trading-ratio system for trading water pollution discharge permits", Journal of Environmental Economics and Management, vol. 49, 2005, pp. 83-102.

[6] T.L. Ng and J.W. Eheart, "Effects of discharge permit trading on water quality reliability", Journal of Water Resources Planning and Management, ASCE, vol. 131, No. 2, 2005, pp. 81-88.

[7] S.M. Mesbah, R. Kerachian and M.R. Nikoo, "Developing real time operating rules for trading discharge permits in rivers: Application of Bayesian Networks", Environmental Modelling and Software, vol. 24, 2009, pp. 238-246.

[8] M.H. Niksokhan, R. Kerachian, and P. Amin, "A stochastic conflict resolution model for trading pollutant discharge permits in river systems", Environmental Monitoring and Assessment, Springer, vol. 154, No. 1-4, 2009, pp. 219-232.

[9] M.H. Niksokhan, R. Kerachian, and M. Karamouz, "Game Theoretic Approach for Trading Discharge Permits in Rivers", Water Science and Technology, IWA, 2009, vol. 60, pp. 793-804.

[10] P. Cole, and W.F. Ritter, "A conceptual framework for assessing the success of water quality trading programs", In proceedings of World Environmental and Water Resources Congress, ASCE, 2010, pp. 623-633.

[11] S.M. Mesbah, R. Kerachian, and A. Torabian, "Trading pollutant discharge permits in rivers using fuzzy nonlinear cost functions", Desalination, vol. 250, 2010, pp. 313-317.

[12] K. Deb, S. Agrawal, A. Pratap, and T. Meyarivan, "A fast elitist non-dominated sorting genetic algorithm for multi-objective optimization: NSGA-II”, KANGAL Report No. 200001, Indian Institute of Technology, Kanpur, India, 2000.

[13] S. Ghosh, and P.P. Mujumdar, "Risk minimization in water quality control problems of a river system", Advances in Water Resources, vol. 29, 2006, pp. 458-470.

[14] O.L. Mangasarian, H. Stone, and M. S. Bajestan, "Two-Person Nonzero-Sum Games and Quadratic Programming", Journal of mathematical analysis and application, Vol. 9, 1964, pp. 348-355.

[15] J. Nash, "Non-cooperative games", Ann. Moth. vol. 54, 1951, pp. 286-295.

[16] H.W. Streeter and E. B. Phelps, "A study of the pollution and natural purification of the Ohio River. III: Factors concerning the phenomena of oxidation and reaeration”. Public Health Bulletin, vol. 146, 1925. 